\title{
Atuação de bolsistas didáticos no Instituto de Química-UNESP, campus de Araraquara: características e implicações acadêmicas desse modelo de prática docente para pós-graduandos
}

\author{
Graduate teaching assistants at the Institute of Chemistry-UNESP, campus \\ Araraquara: features of this docent practice model for graduate students and \\ its implications on the academic environment
}

\begin{abstract}
Actuación de becarios didácticos en el Instituto de Química-UNESP, campus de Araraquara: características e implicaciones académicas de este modelo de práctica docente para estudiantes de posgrado
\end{abstract}

Gabriel Garcia'

'Universidade Estadual Paulista (UNESP) - Campus de Araraquara, São Paulo - Brasil. E-mail: gabrielggh@bol.com.br

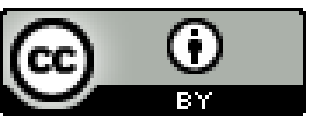

Educação: teoria e prática, Rio Claro, SP, Brasil - eISSN: 1981-8106

Está licenciada sob Licença Creative Common

\section{Resumo}

A prática docente pode representar papel fundamental na formação de pós-graduandos, mas também provocar diversas implicações profundas sobre o ambiente acadêmico como um todo, dependendo do modelo de atuação empregado em cada instituição. Este trabalho procurou avaliar as características do modelo de atuação de bolsistas didáticos aplicado no Instituto de Química-UNESP, campus de Araraquara, e inferir sobre suas consequências sobre a comunidade acadêmica a partir de pesquisa qualitativa com ex-bolsistas. Observou-se que esse modelo de atuação apresenta severa deficiência de mecanismos institucionais de atenuação dos riscos de diminuição da qualidade de ensino de graduação e de comprometimento do desempenho acadêmico em pesquisa de pós-graduandos. Portanto, sugere-se que sua manutenção seja pautada por medidas gerenciais de aprimoramento que desenvolvam e garantam a aplicação de mecanismos de atenuação de prejuízos acadêmicos. 
Palavras-chave: Bolsista didático; Formação acadêmica; Pós-graduação; Qualidade de ensino.

\begin{abstract}
The teaching practice can represent prominent role on graduate student's formation, but also cause a number of profound implications on the academic environment as a whole, depending on the specific applying model. This study objective was to evaluate the characteristics and academic impacts of the graduate students teaching program applied at the Institute of Chemistry - UNESP, Araraquara. As results, severe deficiencies of institutional mechanisms to mitigate impairment of research and teaching activities were observed, therefore it's recommended that the maintenance of this program adopts improving managerial initiatives to implement and assure application of attenuation mechanisms of academic implications.
\end{abstract}

Keywords: Graduate Teaching Assistant; Academic Implications; Undergraduate education quality.

\title{
Resumen
}

La práctica docente puede representar un papel fundamental en la formación de estudiantes de posgrado, pero también provocar diversas implicaciones profundas sobre el ambiente académico como un todo, dependiendo del modelo de actuación empleado en cada institución. Este trabajo procuró evaluar las características del modelo de actuación de becarios didácticos aplicado en el Instituto de Química - UNESP, campus de Araraquara, e inferir sus consecuencias sobre la comunidad académica a partir de la investigación cualitativa con exbecarios. Se observó que este modelo de actuación presenta una severa deficiencia de mecanismos institucionales que atenúen los riesgos de disminución de la calidad de enseñanza de graduación y de comprometimiento del desempeño académico en la investigación de los estudiantes de posgrado. Por tanto, se sugiere que su manutención sea pautada por medidas gerenciales de perfeccionamiento que desarrollen y garantan la aplicación de mecanismos de atenuación de perjuicios académicos.

Palabras clave: Becario didáctico; Formación académica; Posgrado. Calidad de enseñanza.

\section{Introdução}

Nos últimos anos, reflexões e pesquisas sobre aspectos formativos da pós-graduação vêm ganhando crescente destaque, especialmente quanto a seus mecanismos para promoção de desenvolvimento pedagógico e de prática docente a pós-graduandos (ZANON; OLIVEIRA; QUEIROZ, 2009; PIMENTA; ANASTASIOU, 2005). Dentro desse contexto, 
surgiram diferentes modelos para preenchimento dessa histórica lacuna de formação, por exemplo, o estágio de docência estabelecido em portaria da Coordenação de Aperfeiçoamento de Pessoal de Nível Superior (CAPES) e o programa de aperfeiçoamento do ensino (PAE) da Universidade de São Paulo (FEITOSA, 2002; ARROIO, RODRIGUES FILHO; SILVA, 2006; ARROIO et. al. 2008; TEODORO et. al., 2011).

A partir de trabalhos de avaliação dos impactos da prática docente na formação de pós-graduandos pode-se afirmar que tanto a preparação pedagógica antecedente quanto a própria atuação prática são capazes de desenvolver saberes e habilidades essenciais na construção da identidade profissional do futuro docente, portanto, corroboram com a aplicação e manutenção dessas iniciativas (PIMENTA; ANASTASIOU, 2005; ARROIO et al., 2008).

Por outro lado, de maneira geral a atuação de pós-graduandos no ensino desperta preocupações diversas, principalmente relacionadas aos possíveis prejuízos às suas atividades de pesquisa e à qualidade do ensino de graduação. Tanto que modelos de prática docente como o estágio de docência são comumente regidos por medidas que procuram impedir, ou reduzir, esses possíveis prejuízos. Como exemplos dessas medidas é possível citar exigência de preparação pedagógica antecedente, seja em forma de disciplina ou de ciclo de seminários (ZANON; OLIVEIRA; QUEIROZ, 2009; ARROIO; RODRIGUES FILHO; SILVA, 2006), a aplicação de limites de carga horária semanal e porcentagem máxima de aulas ministradas (FEITOSA, 2002; IQ-UNESP, 2011).

Há pouco menos de uma década, a Universidade Estadual Paulista "Júlio de Mesquita Filho" - UNESP estabeleceu outra iniciativa para atuação de doutorandos no ensino de graduação, porém seu contexto de criação e objetivos não se fundamentam no aprimoramento da formação acadêmica, como nos casos anteriormente citados. Nos anos de 2003 e 2004, ocorreram três situações que desafiaram as práticas de gestão dessa instituição: diminuição do repasse de verba pública devido à involução do ICMS, em 2003, no Estado de São Paulo, elevado número de pedidos de aposentadoria de docentes no segundo semestre de 2003 e o impedimento de realização de concursos e admissões a partir de 03 de julho 2004, por se tratar de ano eleitoral (UNESP, 2004).

No contexto referido, foi traçada uma perspectiva de iminente comprometimento da qualidade do ensino (ou até de incapacidade de atendimento da demanda de ensino), fazendo com que, em 26 de maio de 2004, fosse lançado o Ofício circular n. ${ }^{\circ}$ 06/2004-Runesp, (UNESP, 2004), outorgando a utilização dos préstimos de doutorandos para o ensino em nível de graduação, criando, assim, a função de bolsista didático.

De acordo com o referido ofício, o doutorando exerceria até 8 horas semanais de atividade docente em disciplinas de graduação de área correlata ao seu curso de pósgraduação, de maneira remunerada e em concomitância ao desenvolvimento de seu projeto de pesquisa, devendo ser supervisionado pelo orientador ou por docente nomeado pelo departamento para evitar prejuízos ao seu desempenho acadêmico. A nova função teria 
vigência apenas durante o segundo semestre do ano de 2004, já que seriam regularizadas as condições de contratação de docentes no semestre seguinte. No entanto, perdura até hoje.

Da forma como foi concebida e normatizada, a função de bolsista didático é similar ao Graduate Teaching Assistant (GTA), há décadas empregado em instituições internacionais de ensino superior que recorrem à atuação remunerada de doutorandos no ensino de graduação quando enfrentam contextos de aumento de demanda por atividades didáticas sem que haja reajustes correspondentes nos investimentos (PARK; RAMOS, 2002; PARK, 2002, 2004).

Em contraposição à escassez de trabalhos de pesquisa sobre a atuação de bolsistas didáticos (ou sobre outra função equivalente em instituições brasileiras), há vasta literatura disponível com reflexões e relatos de experiências sobre modelos de atuação de GTA's (PARK; RAMOS, 2002; PARK, 2002, 2004). Tais são, portanto, os referenciais teóricos nos quais se fundamentam as primeiras interpretações aqui dedicadas ao atual modelo de prática docente a pós-graduandos em questão.

\section{Apreensões sobre atuação de GTA's}

Neste tipo de atuação docente são exigidos dos doutorandos níveis de dedicação e responsabilidade que provocam profundas implicações positivas e negativas não só em sua formação, mas no ambiente acadêmico como um todo. Reconhecer, com maior nitidez, possíveis benefícios e prejuízos observados na instituição de ensino, no ensino de graduação e na formação de pós-graduandos é subsídio fundamental para resultados bem sucedidos da adoção de GTA's. A seguir encontram-se reflexões a respeitos das implicações já observadas no meio acadêmico, especificamente nos âmbitos da gestão de instituições de ensino e da formação acadêmica de graduandos e pós-graduandos (PARK; RAMOS, 2002).

Sob a óptica institucional, o principal efeito positivo da adoção de GTA's advém de sua própria gênese: o atendimento da crescente demanda por atividades de ensino com investimento relativamente baixo. Paralelamente, ainda atenua a sobrecarga de trabalho dos docentes permitindo-lhes maior dedicação às atividades de pesquisa, sobre as quais a pressão por melhor desempenho tem, também, aumentado significativamente nos anos recentes (PARK; RAMOS, 2002; PARK, 2002). Por outro lado, essa prática tem como principal efeito negativo o risco de diminuição da qualidade de ensino de graduação. Cabe à instituição a responsabilidade de minimizá-lo, aplicando as medidas apropriadas a cada situação específica, e que frequentemente estão associadas a aperfeiçoamento do desempenho didático do GTA (PARK; RAMOS, 2002).

No âmbito dos alunos de graduação, a prática docente como GTA's também pode ter como principal efeito negativo a diminuição da qualidade de ensino decorrente de desempenho didático insatisfatório. Além disso, de certa forma sua atuação pode limitar o contato dos graduandos com pesquisadores experientes e, consequentemente, o acesso às atividades de pesquisa de excelência. Por outro lado, não se pode desconsiderar o efeito positivo mais evidente, que é uma relação interpessoal entre graduandos e GTA's mais 
próxima do que entre graduandos e docentes, o que pode conferir maior eficiência a alguns aspectos do processo de ensino-aprendizagem, como identificação de dificuldade dos alunos, escolha de linguagem e abordagens didáticas, entre outros (PARK; RAMOS, 2002).

No âmbito dos pós-graduandos os principais efeitos positivos e negativos recaem sobre sua formação acadêmica. Considera-se que a experiência didática, vivenciada por GTA's, pode ser muito positiva por contribuir profundamente para aceleração de seu desenvolvimento profissional e pessoal, permitindo construção de sua identidade docente em atividades de ensino-aprendizagem e aumento do sentimento de autoconfiança, que pode, inclusive, provocar ganho de desempenho em outros escopos profissionais (PARK; RAMOS, 2002). Em contrapartida, a dedicação e a carga de trabalho envolvidas nessa atividade podem sobrecarregar os pós-graduandos a ponto de prejudicar seu desempenho em pesquisa, o que causaria maior lentidão na obtenção de resultados e no avanço do trabalho. Nesse sentido, os prejuízos afetariam não somente o pós-graduando, mas, inclusive, os indicadores de produção científica e o desempenho acadêmico da instituição.

Portanto, a adoção bem sucedida de GTA's no ensino de graduação deve ser resultado do equilíbrio entre o suprimento da demanda de ensino institucional e atenuação dos riscos de diminuição de qualidade do ensino e diminuição do desempenho acadêmico em pesquisa de pós-graduandos (que se reflete sobre o desempenho da própria instituição de modo geral). Dessa forma, cabe à instituição estabelecer modelos de atuação com características apropriadas para manutenção do equilíbrio.

Especificamente a esse respeito, há relativa abundância de trabalhos disponíveis com as principais apreensões sobre modelos de atuação de GTA's aplicados por instituições internacionais. A partir de experiências de instituições norte americanas, Park (2004) sumariza os principais mecanismos institucionais de atenuação dos possíveis prejuízos na busca pelo referido equilíbrio, categorizando esses mecanismos em três escopos mais relevantes, apresentados a seguir: seleção, treinamento e supervisão dos GTA's.

O processo de seleção deve ser consistente e se conduzir por preceitos éticos fundamentais como justiça e transparência. Além disso, na seleção devem ser considerados todos os critérios que tenham relação direta com a eficiência da atuação do futuro GTA. Entre os principais critérios de seleção empregados estão: domínio do conhecimento específico a ser lecionado, participação de treinamento antecedente e experiência didática. (PICKERING, 1988; YULE; HOFFMAN, 1990).

Treinamento pode ser definido como o processo que procura desenvolver, por instrução e prática, um padrão mínimo de qualidade de desempenho didático do GTA, ou do aspirante a GTA. Grandes esforços têm sido dedicados a esse aspecto pelas instituições americanas e, consequentemente, são inúmeros os exemplos de desenvolvimento e avaliação dos impactos de programas de treinamento descritos na literatura (PARK, 2004).

Conteúdo, forma e estratégias variam enormemente nesses exemplos, dependendo dos objetivos específicos e necessidades de cada área do conhecimento, da instituição e inclusive dos próprios GTA’s. Já foram descritas estratégias construtivistas de aprendizagem, 
iniciativas de tutoria por pares e outras baseadas em aspectos motivacionais. Existem, também, programas aplicados por profissionais especializados e dedicados exclusivamente aos treinamentos ou por docentes experientes com reconhecida competência em ensino (KNOTTS; MAIN, 1990; ROBINSON, 2000; RALPH, 2001; PARK, 2004).

Relatos constatam que GTA's submetidos a um programa de treinamento antecedente à atividade docente apresentaram desempenho claramente superior ao daqueles que não foram submetidos a ele (PRIETO; ALTMAIER, 1994). Tais evidências argumentam que essa etapa de preparação prévia do GTA pode ser vital para garantia de padrão mínimo de qualidade no ensino de graduação.

A supervisão do GTA envolve acompanhamento contínuo de suas atividades durante todo o período de atuação e avaliação de desempenho para aprimoramento da sua prática docente. É desempenhada com maior frequência por docente corresponsável pela disciplina em que atua, embora possa também ser de responsabilidade do orientador ou ainda, em mais raros casos, ser respaldada por GTA's mais experientes em tutorias por pares. (PARK, 2004). De acordo com Yule e Hoffman (1993) as opiniões e avaliações pontuais dos alunos de graduação com relação à atuação dos GTA's se mostraram valiosamente informativas, logo poderiam ser consideradas como suporte à avaliação de desempenho feita pelo supervisor.

Essa visão geral sobre a temática de modelos de atuação de GTA's permite observar que, embora do ponto de vista da gestão institucional a adoção de doutorandos no ensino de graduação seja estrategicamente conveniente, a instituição deve apresentar como contrapartida um modelo adequado que minimize todos os seus possíveis prejuízos. Como a atuação de bolsistas didáticos figura como um desses espaços de prática docente para pósgraduandos, sua adoção e manutenção prolongada devem se pautar, também, por avaliação de suas implicações acadêmicas e pelo estabelecimento de um modelo que previna possíveis prejuízos.

\section{Objetivos}

Nesse sentido, os objetivos deste trabalho foram avaliar as características do atual modelo de atuação de bolsistas didáticos aplicado no Instituto de Química-UNESP, campus de Araraquara, e, a partir dessas características, inferir sobre suas possíveis implicações acadêmicas, traçando paralelos com os referenciais teóricos descritos, podendo, assim, orientar futuras medidas de gerenciamento desse espaço de prática docente.

\section{Abordagem metodológica}

Para alcançar os objetivos, optou-se por uma abordagem metodológica com emprego de pesquisa qualitativa detalhada, aplicada ao contexto dos pós-graduandos que atuaram como bolsistas didáticos. A princípio, o trabalho também poderia se utilizar de análise de 
documentos oficiais e contribuições dos atores envolvidos nos outros escopos (instituição e graduação), no entanto, distintas restrições a essas iniciativas direcionaram o trabalho para esta estratégia mais específica.

Nesta pesquisa, a coleta de dados qualitativos foi conduzida pela aplicação de questionário a pós-graduandos do Instituto de Química, ou egressos já titulados, que atuaram como bolsista didático por pelo menos um semestre completo. O questionário (ANEXO I) foi composto por doze perguntas abertas (MOREIRA, 2010) que dialogam com todos os aspectos discutidos nos referenciais teóricos. Ou seja, o conteúdo das questões foi dividido em âmbitos que buscam obter informações a respeito das características e critérios dos mecanismos institucionais de seleção, treinamento e supervisão, bem como das apreensões dos ex-bolsistas acerca dos impactos negativos e positivos observados em sua formação acadêmica enquanto pós-graduandos.

Nesse sentido, julga-se que a articulação dessas contribuições e apreensões de exbolsistas com os referenciais teóricos adotados é capaz de fornecer subsídios adequados para uma análise mais abrangente, permitindo inferir sobre implicações nos outros âmbitos acadêmicos não contemplados na pesquisa qualitativa.

Para a coleta de dados, realizada no segundo semestre de 2012, os ex-bolsistas foram convidados a contribuir com a pesquisa por correio eletrônico institucional, ao qual têm acesso tanto alunos atuais quanto egressos do programa de pós-graduação em química. No total quinze ex-bolsistas responderam ao convite, manifestando interesse em participar da pesquisa, aos quais, então, foi enviado o questionário. Dentre estes ex-bolsistas, treze responderam ao questionário e enviaram suas respostas também por correio eletrônico, e dois se abstiveram de responder, sem dedicar justificativas à abstenção. As respostas recolhidas pelos treze participantes (disponíveis no ANEXO II) são interpretadas e discutidas a seguir, mantendo-se o anonimato aos respondentes que são identificados, doravante, por numeração de 1 a 13.

\section{Resultados e interpretações}

Inicialmente, com as primeiras duas perguntas procurou-se conhecer a data do início da atuação como bolsista e durante qual período do doutorado a atuação foi exercida pelo pósgraduando. Foram recolhidas contribuições de bolsistas didáticos que atuaram entre os anos de 2006 a 2012. Há exemplos distintos de duração dessas atuações, como por apenas um semestre (5 respondentes), por dois semestres consecutivos (6 respondentes), por três semestres consecutivos ( 1 respondente) e por quatro semestres consecutivos (1 respondente). Há grande diversidade, também, com relação a qual período do doutorado a função de bolsista foi exercida, com exemplos de pós-graduandos que iniciaram atuação de bolsista didático a partir do mesmo semestre de ingresso no doutorado, como exemplos de atuação como bolsista somente no período final do doutorado. 
As perguntas 3 a 7 tiveram objetivo de avaliar as características dos mecanismos institucionais aplicados nessa instituição, e interpretar os possíveis impactos sobre a formação de pós-graduandos e sobre a comunidade acadêmica com um todo. Nas respostas às perguntas 3 e 4, com relação às características e critérios da etapa de seleção de bolsistas, foram descritos 3 tipos distintos de experiências: seleção com prova didática (sete respondentes), ausência de seleção por haver candidato único (quatro respondentes) ou ausência de seleção com ingresso por convite feito por docente (dois respondentes).

A maioria dos respondentes passou por processo de seleção que envolvia prova didática sobre tópico relacionado à disciplina em que atuariam. Em dois desses casos (respondentes 1 e 7) havia também uma prova escrita sobre o conteúdo da disciplina. Em outros dois casos (respondentes 5 e 6) houve análise de currículo ou histórico além da prova didática. Todos esses respondentes citaram o desempenho na prova didática como critério mais relevante na seleção.

Cabe ressaltar que o respondente 6 justifica a análise de histórico na seleção pois “[...] era exigido que o candidato já tivesse feito exame de qualificação." Essa regra restritiva ao pleito à vaga de bolsista selecionaria os alunos que já tivessem concluído parte significativa de seus projetos de pesquisa, portanto, aparentemente, teria o objetivo de diminuir os prejuízos ao andamento dessas atividades, logo à formação dos pós-graduandos de maneira geral.

A atuação deste respondente (6) como bolsista didático, que teve início em 2006, é o exemplo mais antigo de atuação recolhido e em nenhuma outra atuação subsequente foi observada existência dessa ou de qualquer outra regra restritiva ao pleito. Tal restrição limita o número de possíveis candidatos às vagas de bolsista, logo a atual ausência de restrições na seleção pode se relacionar com tendência de procura reduzida pela atuação como bolsista, observada no segundo tipo de seleção mais frequentemente citado nas respostas e comentado a seguir.

Quatro respondentes $(2,3,10$ e 13) descreveram não ter havido seleção porque foram candidatos únicos à vaga de bolsista didático que cada um pleiteava. Dois deles justificam que haveria seleção, porém, em um caso houve apenas um inscrito e, no outro caso, os demais inscritos desistiram durante a seleção. Os outros dois respondentes não comentaram se haveria ou não processo de seleção.

Por fim, dois respondentes (4 e 12) comentaram que ingressaram na atuação como bolsistas didáticos por convite. Um deles justifica que "[...] houve problemas de âmbito institucional com o bolsista que iria atuar nesse período [...]” e o outro não dedica comentário algum.

A pergunta 5 (Você participou de alguma atividade de aprimoramento de desempenho em aspectos didáticos antes de se tornar bolsista didático? Se sim: descreva as características desta atividade. Se não: existe um motivo para a não participação? Qual?) diz respeito ao treinamento. A resposta do respondente 7 apresentou uma definição clara sobre esse mecanismo institucional que também permeou todas as outras respostas: "Não. Não foi 
oferecida pela instituição nenhuma atividade de aprimoramento didático que estivesse diretamente relacionada com a formação dos bolsistas didáticos."

Cinco respondentes $(2,4,6,7$ e 13) declararam não ter participado dessas atividades de aprimoramento, por não existir nenhuma iniciativa diretamente associada ao contexto do bolsista didático. No entanto, parte desses respondentes (2, 6 e 13) enfatizou a relevância de experiências práticas prévias obtidas no curso de graduação em licenciatura em química e no exercício de estágios de docência durante a pós-graduação para esse aprimoramento.

Os outros respondentes $(1,3,5,8,10,11$ e 12) associaram totalmente experiências prévias diversas à atividade de aprimoramento de desempenho citada na pergunta, sem reconhecer a possibilidade, ou necessidade, do oferecimento de uma iniciativa diretamente associada ao contexto específico do bolsista didático. Entre as experiências prévias citadas por esses respondentes estão, em ordem decrescente de frequência de citações, estágio de docência, iniciativas (teóricas e práticas) oriundas do curso de licenciatura, disciplina pedagógica cursada na pós-graduação e exercício de monitoria durante a graduação.

Dentre essas experiências, estágio de docência e disciplina pedagógica do programa de pós-graduação foram as únicas que, de alguma forma, se aproximam do preconizado nos referenciais teóricos, ou seja, iniciativas de preparação de um pós-graduando para a docência em nível superior e, portanto, são as únicas que poderiam ser consideradas como treinamento por aspirantes a bolsista didático.

Entretanto, todos os exemplos de atuação recolhidos demonstraram que o treinamento é facultativo àquele que pleiteia o exercício da função de bolsista didático, assim a maioria dos respondentes $(1,2,8,9,11,12$, e 13) não comentou ter exercido nenhum dos dois possíveis treinamentos considerados (estágio de docência ou disciplina pedagógica na pósgraduação), como fica demonstrado na fala do respondente 11: "Não participei porque não fiz licenciatura; durante o mestrado não fiz estágio docência porque era bolsista CNPq e não era obrigado a fazer." Nesses casos, desenha-se um cenário de maior suscetibilidade ao comprometimento da qualidade do ensino e a prejuízos à formação de graduandos e pósgraduandos.

Nas respostas à pergunta 6 (Houve algum tipo de supervisão de sua atuação como bolsista didático? Se sim: Como foi esta supervisão? E por quem essa função foi desempenhada?), observou-se que apenas uma minoria dos casos (respondentes 2, 3, 12 e 13) descreveu ter havido supervisão contínua durante o período de atuação como bolsista, que envolveu orientação no preparo das aulas e de atividades diversas, bem como avaliações de desempenho do bolsista. Nesses casos, a supervisão foi exercida tanto pelo docente corresponsável pela disciplina (2, 3 e 12), como também pelo orientador (2) e por outros professores do departamento (13).

Por outro lado, a maioria dos casos (respondentes 4 a 11) descreveu exemplos de ausência de supervisão. Alguns deles citaram o acompanhamento de parte de suas aulas pelos docentes corresponsáveis pela disciplina (principalmente em aulas práticas, casos em que as 
turmas são divididas entre docentes), mas que não implicaram em nenhum outro exercício de supervisão como as atividades já citadas.

Ainda, com relação à supervisão, destaca-se a fala do respondente 4: "Não houve supervisão durante minha atuação como bolsista, mas os professores com os quais compartilhei as turmas sempre foram solícitos quanto ao auxílio didático antes e durante as aulas." Essa resposta sugere que o contato do bolsista com o docente que deveria exercer a supervisão é facultativo (condição semelhante ao treinamento) e sujeito à necessidade eventual do bolsista, quando deveria ser contínuo, desenhando outra vez o cenário de maior suscetibilidade ao comprometimento da qualidade do ensino e a prejuízos à formação de graduandos e pós-graduandos.

A pergunta 7 (Seu desempenho como bolsista sofreu alguma avaliação? Se sim: a avaliação foi efetuada por quem? E quais os critérios mais relevantes observados, em sua opinião?) trata da avaliação com objetivo de aprimoramento do desempenho do bolsista, parte das responsabilidades do exercício de supervisão.

Pôde-se observar, nas respostas, que houve avaliação em somente três casos (respondentes 1, 3 e 10). No primeiro deles (respondente 1) a avaliação foi feita por aplicação de questionários aos alunos e, posteriormente, encaminhada ao chefe de departamento e ao bolsista. Nos outros dois casos a avaliação foi realizada pelo supervisor de maneira não pontual, ao longo do período de atuação, no exercício de cada atividade dos bolsistas como preparo de avaliações, planejamento e execução do conteúdo programático e preparo de aulas.

No restante dos casos ficou evidente a ausência de avaliação de qualquer tipo, o que consequentemente representa deficiência no processo de aprimoramento da prática docente do pós-graduando que atua como bolsista. Cabe destacar, ainda, o comentário do respondente 9: "Sei que o professor responsável fez uma avaliação, mas não tenho conhecimento sobre". Nota-se que, apesar de ter havido avaliação, a mesma não cumpriu papel algum no aprimoramento da prática docente do bolsista, portanto, outro exemplo de avaliação deficiente.

A partir daqui são discutidas as perguntas 8 a 10 , que têm relação direta com as concepções dos ex-bolsistas sobre as implicações desse modelo de atuação de bolsistas didáticos na formação acadêmica dos pós-graduandos.

As contribuições dos respondentes à pergunta 8 (Existem fatos ou situações que influenciaram sua decisão sobre a escolha por atuar apenas por um semestre ou por mais de um semestre? Por favor, comente.) permitem constatar que há um controle autônomo por parte do bolsista sobre a decisão de ingresso e de duração de sua atuação, cuja única condição reguladora parece ser a manutenção do equilíbrio entre seu desenvolvimento profissional e prejuízos às suas atividades de pesquisa. Nenhum comentário foi dedicado sobre consideração de outros critérios como avaliação de desempenho e da qualidade de ensino para respaldar a continuidade da atuação do bolsista. 
Observam-se nas contribuições dos respondentes 1, 2 e 11, respectivamente transcritos a seguir, três claros exemplos dessa regulação:

Em 2008, abriu vaga para seleção de bolsista didático [...]. Porém, como estava muito atarefado com experimentação no laboratório além de cursar disciplinas, resolvi não prestar a seleção. No $2^{\circ}$ semestre de 2009 , as disciplinas já haviam terminado além de estar com muitos resultados experimentais do doutorado, resolvi prestar a seleção.

Meu crescimento profissional ministrando estas aulas foi muito satisfatório para mim. Desta forma decidi continuar mais um semestre.

[...] resolvi não continuar por um terceiro semestre porque acredito que é uma atividade que necessita de muita dedicação, o que pode levar ao não cumprimento do prazo de finalização do doutorado.

Nas respostas às perguntas 9 e 10 (sobre quais foram os efeitos positivos e negativos causados pela atuação como bolsista didático na formação acadêmica dos pós-graduandos?) as consequências desse equilíbrio foram colocadas em evidência. Todos os efeitos positivos observados desdobram-se a partir do desenvolvimento profissional e construção de identidade docente dos pós-graduandos, por exemplo:

[...] me possibilitou aprender a ser mais objetiva, a ter mais desenvoltura em sala e dimensionar melhor tempo e conteúdo das aulas.

O principal aspecto positivo foi a confirmação de seguir carreira como docente no ensino superior [...].

Os efeitos do programa foram todos positivos em minha formação. Aprendi a organizar-me e portar-me como profissional, ganhei experiência e mais segurança em sala de aula, vivenciei o ambiente dos professores no qual obtive inclusive ensinamentos de vida, fiz contatos profissionais e ainda contribui para o meu currículo.

Com relação aos prejuízos sobre a formação acadêmica dos pós-graduandos, cinco respondentes $(4,8,9,10$ e 13$)$ declararam não ter observado quaisquer efeitos negativos em decorrência da atuação como bolsista. Todos os outros respondentes apontaram algum tipo de prejuízo. Os respondentes 1, 2, 3, 7, 11 e 12 comentaram sobre possíveis prejuízos resultantes do tempo necessário para se dedicar à atuação como bolsista didático concomitantemente às atividades de pesquisa, novamente evidenciando o mecanismo regulador citado anteriormente, como se pode observar nos comentários transcritos a seguir:

Não tive aspectos negativos, por ter me organizado antes de entrar como bolsista. [...] Mas como se trata de uma atividade que demanda tempo e dedicação do bolsista, acredito que se o aluno não se organizar muito bem, as atividades de pesquisa e de ensino poderão ser prejudicadas. 
Não vejo pontos negativos. Confesso que o tempo que apliquei na preparação das aulas me atrapalhou um pouco no desenvolvimento do meu projeto de doutorado, mas em um balanço total acredito que ganhei bastante.

Não encontrei efeitos negativos em minha formação. [...] Por outro lado, vale salientar que ministrar certa disciplina pela primeira vez requer bastante dedicação e tempo para a preparação das aulas, consumindo parte do tempo que poderia ser dedicado ao desenvolvimento da tese de doutorado.

Como sobrava pouco tempo para me dedicar ao projeto de doutorado, pois fazia disciplina e era bolsista didático [...] meu orientador se incomodou comigo e de certa forma me colocou de lado.

\section{Discussão}

A seleção parece ser o mecanismo institucional aplicado com maiores frequência e eficiência, considerando critérios relacionados ao desempenho do bolsista na maioria dos casos recolhidos. Situações em que não foram aplicados processos de seleção relacionam-se à ausência de outros candidatos pelo pleito à função de bolsista didático, fato que pode ter contribuído para a extinção de regras restritivas ao pleito ao exercício da função de bolsista didático que minimizariam prejuízos à formação de pós-graduandos.

Já com relação ao treinamento, observou-se que não existe iniciativa de aprimoramento de desempenho diretamente aplicada ao contexto de atuação do bolsista didático. Assim, outras iniciativas como estágio de docência e disciplina pedagógica oferecida pelo programa de pós-graduação podem ser facultativamente adotadas em substituição ao treinamento. Porém, a atuação de bolsistas sem qualquer preparação pedagógica teórica ou experiência de prática docente exercida durante a pós-graduação representaram a maioria das contribuições recolhidas.

Outra constatação foi a ausência, na maioria dos casos, de supervisão contínua e avaliação de desempenho do bolsista, instrumentos essenciais no aprimoramento de sua prática docente. Nos poucos casos em que os processos de supervisão e avaliação ocorreram, foram resultado da iniciativa individual de alguns docentes e bolsistas.

De acordo com essas considerações, observou-se que somente a minoria dos casos descritos apresentou exemplos de aplicações bem sucedidas dos mecanismos institucionais preconizados nos referenciais teóricos para atenuação dos possíveis prejuízos acadêmicos decorrentes da atuação dos bolsistas. Portanto, pode-se considerar que, em um saldo geral, o modelo de atuação de bolsistas didáticos em questão apresenta insuficiência desses mecanismos, cujas consequências impactam diretamente sobre a formação tanto de pósgraduandos quanto de graduandos.

A propósito, consequências sobre a formação de graduandos raramente foram consideradas pelos pós-graduandos, com exceção feita ao caso descrito pelo respondente 5. Em sua resposta à pergunta sobre características da supervisão, observa-se um problema de 
ordem de planejamento e execução da disciplina, responsabilidades dele próprio e também do supervisor no exercício de sua função:

[...] o professor responsável acabava por vezes me deixando responsável por mais aulas do que era de minha responsabilidade, chegando ao ponto de eu ser comunicada de 30 a 10 minutos antes da aula que o professor responsável pelo dia não poderia estar presente e me deixando responsável por ministrar aulas teóricas de 4 horas. Diante de toda esta situação decidi por não continuar como bolsista.

E à pergunta 10 (sobre os prejuízos à sua formação acadêmica) responde de maneira complementar: "Acredito que não houve efeitos negativos para minha formação (...). Para os alunos, entretanto, creio que o melhor planejamento e cumprimento do cronograma teria resultado em melhor formação."

Esse caso figura como um exemplo extremo de deficiência de supervisão, a princípio não representativo das condições gerais encontradas pelos bolsistas. Porém, demonstra que a ausência (ou ineficiência) das iniciativas de aprimoramento de desempenho do bolsista (nesse caso, supervisão) resultou em diminuição da qualidade de ensino de graduação mesmo não tendo comprometido a formação do pós-graduando. Como distintas ineficiências dessas iniciativas foram observadas com frequência, talvez seja o indício de que a formação de graduandos pode ser frequentemente prejudicada, mesmo que em menor intensidade do que nesse caso específico.

Não obstante, o saneamento de deficiências institucionais é a principal componente das contribuições dos respondentes à pergunta 11 (Você tem alguma sugestão para o aprimoramento do modelo de atuação do bolsista didático?). A grande maioria das sugestões diz respeito ao aprimoramento dos mecanismos institucionais, com exemplos relacionados à seleção (respondentes 8 e 12), treinamento (respondentes 1, 2, 4) e, principalmente, supervisão $(6,7,8,10,11$ e 12).

\section{Considerações finais}

O modelo de atuação de bolsistas didáticos figura como um espaço de prática docente em nível superior que requer altos níveis de dedicação e responsabilidade por parte dos pósgraduandos nele envolvidos, e tem profundas implicações no ambiente acadêmico. A adoção prolongada bem sucedida de modelos semelhantes em instituições internacionais se mostrou resultado da aplicação de mecanismos institucionais para atenuação dos prejuízos ao desempenho acadêmico em pesquisa de pós-graduandos e à qualidade do ensino de graduação. Neste estudo, observou-se severa deficiência desses mecanismos no modelo analisado, principalmente aqueles relacionados ao aprimoramento do desempenho didático do bolsista, o que aponta para possível suscetibilidade aos prejuízos citados. 
É importante destacar que, a despeito dessa deficiência, foram observados benefícios relevantes no desenvolvimento profissional de pós-graduandos em decorrência dessa prática docente. Além disso, aparentemente os prejuízos às suas atividades de pesquisa puderam ser reduzidos satisfatoriamente com controle autônomo do bolsista sobre período e duração de sua atuação. Tais observações demonstram ser possível alcançar saldo positivo ante os efeitos gerais desse tipo de atividade docente sobre a formação acadêmica de doutorandos, por isso, argumentam favoravelmente à sua adoção e manutenção.

No entanto, a garantia de qualidade do ensino de graduação foi apenas raramente considerada nos exemplos de atuação recolhidos, devido à já citada deficiência do modelo e à negligência desse aspecto na avaliação da atuação de cada bolsista. De maneira que a formação acadêmica de graduandos submetidos à atuação de bolsistas didáticos está, possivelmente, sujeita aos mais significativos e frequentes prejuízos decorrentes desse atual modelo.

Embora as conclusões possam não se aplicar a um universo mais amplo, são argumentos suficientes para sugerir que a aplicação contínua e bem sucedida desse espaço específico de prática docente a pós-graduandos é possível, mas deve ser pautada por medidas gerenciais de aprimoramento do modelo atual. Tal aprimoramento pode seguir distintas estratégias, haja vista a diversidade de modelos bem sucedidos consultados como referenciais, bem como a diversidade de sugestões dedicadas pelos ex-bolsistas. No entanto, o aspecto comum a todas elas é a demanda por uma readequação essencialmente paradigmática, na qual a valorização da formação de pós-graduandos e, principalmente a garantia da qualidade de ensino de graduação, devem ser conceitos soberanos em relação à urgência gerencial da instituição no atendimento da demanda de ensino.

\section{Referências}

ARROIO, A.; RODRIGUES FILHO, U. P.; da SILVA, A. B. F. A formação do PósGraduando em Química para a docência em nível superior. Química Nova, São Paulo, v. 29, n. 6, p. 1387-1392, ago. 2006.

ARROIO, A.; HONÓRIO, K. M.; HOMEM-DE-MELO, P.; WEBER, K. C.; da SILVA, A. B. F. A prática docente do Pós-Graduando em Química. Química Nova, São Paulo, v. 31, n. 7, p. 1888-1891, set. 2008.

FEITOSA, J. P. A. Construindo o estágio de docência da Pós-Graduação em Química. Química Nova, São Paulo, v. 25, n. 1, p. 153-158, 2002.

IQ-UNESP. Norma interna $\mathbf{n}^{\mathbf{0}} \mathbf{0 0 1 / 2 0 1 1}$. Normas internas referentes a estágio de docência. Aprovadas pelos conselhos dos Programas de Pós-Graduação em Química e de PósGraduação em Biotecnologia. Disponível em <http://fi.com.br/projetos/unesp/index.php?pagina=formularios $>$. Acesso em: 5 mai. 2012. 
KNOTTS, H. G.; MAIN, E. C. Teaching PhD students to teach Political Science: the Emory TATTO program. PS: Political Science and Politics, Cambridge, v. 32, n. 3, p.607-610, Sep. 1999.

MOREIRA, M. A. Questionários. In: .; VEIT, E. A. (Orgs.). Ensino Superior: Bases

Teóricas e Metodológicas. 2ed. Porto Alegre: E.P.U, 2010. p. 163-171.

PARK, C.; The Graduate Teaching Assistant (GTA): Lessons from North American Experience. Teaching in Higher Education, London, v. 9, n.3, p. 349-361, jul. 2004.

PARK, C. Neither fish nor fowl? The perceived benefits and problems of using Graduate Teaching Assistants (GTAs) to teach undergraduate students. Higher Education Review, Bristol, v.35, n.1, p. 50-62, 2002.

PARK, C.; RAMOS, M. The donkey in the department? Insights into the Graduate Teaching Assistant (GTA) experience in the UK. Journal of Graduate Education, Lancaster, v. 3, n. 2, p. 47-53, 2002.

PIMENTA, S. P.; ANASTASIOU, L. G. C. Docência no Ensino Superior. 2ed. São Paulo: Cortez, 2005.

PICKERING, M. Teaching the large course: can ability as a teaching assistant be predicted? Journal of College Science Teaching, Arlington, v. 18, n. 1, p. 55-56, 1988.

PRIETO, L. R.; ALTMAIER, E. M. The relationship of prior training and previous teaching experience to self-efficacy among graduate teaching assistants. Research in Higher Education, Tallahassee, v.35, n.4, p. 481-497, 1994.

RALPH, E. G. Effective instruction: a synthesis of research-based principles for GTAs.

Journal of Graduate Teaching Assistant Development, Stillwater, v. 8, n.1, p.13-20, 2001.

ROBINSON, J. B. New teaching assistants facilitate active learning in Chemistry laboratories: promoting teaching assistant learning through formative assessment and peer review. Journal of Graduate Teaching Assistant Development, Stillwater, v. 7, n.3, p.147162,2000 .

TEODORO, D. L.; PAGOTTO, J. F.; MOTHEO, A. J.; QUEIROZ, S. L. Formação docente no ensino superior de química: contribuições dos programas de aperfeiçoamento de ensino. Química Nova, São Paulo, v. 34, n. 4, p. 714-719, fev. 2011.

UNESP. Ofício Circular n. ${ }^{\circ} 06$ /2004. Runesp. Disponível em: <http://www.ibilce.unesp.br/administracao/dta/bolsistadidatico/index.php>. Acesso em: 17 out. de 2011; Disponível em: 〈http://web.fc.unesp.br/\#!/administracao/divisao-tecnicaacademica/legislacao/bolsista-didatico/>. Acesso em: 12 nov. 2012; Disponível em: <http://www.unesp.br/portal\#!/crh/manuais/>. Acesso em: 15 nov. 2012. 
YULE, G.; HOFFMAN, P. Predicting success for international teaching assistant in a US University. TESOL Quarterly, Alexandria, v. 24, n.2, p.227-243, 1990.

YULE, G.; HOFFMAN, P. Enlisting the help of US undergraduates in evaluating international teaching assistants, TESOL Quarterly, Alexandria, v. 27, n.2, p. 323-327, 1993.

ZANON, D. A. V.; de OLIVEIRA, J. S. R.; QUEIROZ, S. L. O “Saber” e o "Saber fazer" necessários à atividade docente no ensino superior: visões de alunos de pós-graduação em química. Ensaio Pesquisa em educação em Ciência, Belo Horizonte, v. 11, n. 1, p.1-20, jun. 2009.

Recebido em: março 2013

Aprovado para publicação em: julho 2013 


\section{ANEXO I}

\section{Questionário}

I. Quais são as datas de Início e término do seu curso de doutorado (mês/ano)?

II. Indique o período em que atuou como bolsista citando semestre e ano. (Ex.: atuei no segundo semestre de 2006 e no primeiro semestre de 2007).

III. Como foi a etapa de seleção à qual você foi submetido(a) para atuar como bolsista didático?

IV. Em sua opinião, quais foram os critérios mais relevantes nesta seleção?

V. Você participou de alguma atividade de aprimoramento de desempenho em aspectos didáticos antes de se tornar bolsista didático? Se sim: descreva as características desta atividade. Se não: existe um motivo para a não participação? Qual?

VI. Houve algum tipo de supervisão de sua atuação como bolsista didático? Se sim, como foi esta supervisão? E por quem esta função foi desempenhada?

VII. Seu desempenho como bolsista sofreu alguma avaliação? Se sim, esta avaliação foi efetuada por quem? E quais os critérios mais relevantes observados, em sua opinião?

VIII. Existem fatos ou situações que influenciaram sua decisão sobre a escolha por atuar apenas por um semestre ou por mais de um semestre? Por favor, comente.

IX. Em sua opinião, quais foram os efeitos positivos causados pela atuação como bolsista didático em sua formação acadêmica?

X. E quais foram os efeitos negativos causados pela atuação como bolsista didático em sua formação acadêmica?

XI. Você tem alguma sugestão para o aprimoramento do modelo de atuação do bolsista didático?

XII. Deseja fazer algum comentário sobre qualquer outro aspecto do bolsista didático? 